\title{
Potential Anticancer Properties of Grape Antioxidants
}

\author{
Kequan Zhou' ${ }^{1}$ and Julian J. Raffoul ${ }^{2}$ \\ ${ }^{1}$ Department of Nutrition and Food Science, Wayne State University, Detroit, MI 48202, USA \\ ${ }^{2}$ Department of Medicine, Emory University School of Medicine, Atlanta, GA 30322, USA
}

Correspondence should be addressed to Kequan Zhou, kzhou@wayne.edu

Received 25 May 2012; Accepted 10 July 2012

Academic Editor: Gilda G. Hillman

Copyright ( 92012 K. Zhou and J. J. Raffoul. This is an open access article distributed under the Creative Commons Attribution License, which permits unrestricted use, distribution, and reproduction in any medium, provided the original work is properly cited.

Dietary intake of foods rich in antioxidant properties is suggested to be cancer protective. Foods rich in antioxidant properties include grape (Vitis vinifera), one of the world's largest fruit crops and most commonly consumed fruits in the world. The composition and cancer-protective effects of major phenolic antioxidants in grape skin and seed extracts are discussed in this review. Grape skin and seed extracts exert strong free radical scavenging and chelating activities and inhibit lipid oxidation in various food and cell models in vitro. The use of grape antioxidants are promising against a broad range of cancer cells by targeting epidermal growth factor receptor (EGFR) and its downstream pathways, inhibiting over-expression of COX-2 and prostaglandin E2 receptors, or modifying estrogen receptor pathways, resulting in cell cycle arrest and apoptosis. Interestingly, some of these activities were also demonstrated in animal models. However, in vivo studies have demonstrated inconsistent antioxidant efficacy. Nonetheless, a growing body of evidence from human clinical trials has demonstrated that consumption of grape, wine and grape juice exerts many health-promoting and possible anti-cancer effects. Thus, grape skin and seed extracts have great potential in cancer prevention and further investigation into this exciting field is warranted.

\section{Introduction}

Grape (Vitis vinifera) is one of the world's largest fruit crops. Grape is also one of the most commonly consumed fruits in the world both as fresh fruit (table grape) and processed fruit (wine, grape juice, molasses, and raisins) [1,2]. There are greater than one hundred grape species which are divided into 2 subgenera: Euvitis and Muscadinia. Most of the species are in Euvitis subgenera [3]. Commercially cultivated grapes are usually classified as table or wine grapes depending on their intended method of consumption [4]. Table grapes usually bear large, seedless fruit berries with relatively thin skin, whereas wine grapes are smaller with thick skins [5]. Grapes are known to contain substantial amount of simple sugars especially glucose and fructose. For instance, wine grapes usually contain 19\% or higher sugar content by fresh weight [6]. A growing body of epidemiological studies and randomized controlled human trials have associated the consumption of grapes, wine, and grape juice with a wide variety of health-promoting effects particularly the reduced risk of cardiovascular diseases, type-2 diabetes, certain types of cancers, and other chronic complications [7-13].

\section{Phenolic Antioxidants in Grapes}

The beneficial effects of grape and relevant grape-derived food products are believed to be related to a variety of bioactive components in grapes [14-16]. One major group of these components is phenolic antioxidants typically including anthocyanins, catechins, resveratrol, phenolic acids, and procyanidins [17]. Based on our analysis, 100 grams of fresh grapes contain 63-182 mg of the phenolic compounds [18]. Flavonoids constitute the majority of phenolic compounds $(65-76 \%)$ in grapes. In red grapes, anthocyanins are the major group of the flavonoids [18]. Most of grape phenolic antioxidants are distributed in grape skins or seeds [19]. For instance, resveratrols, antochyanins, and catechins are concentrated in the skin part, while procyanidins are concentrated in grape seeds [20]. The commercial grape skin or seed extracts are made from grape pomace which is typically 
regarded as a waste byproduct generated in the lucrative winemaking industry [21]. Large amounts of this byproduct accumulate annually which leads to a waste-management issue [22]. It is estimated that the harvested grapes will generate approximately $20 \%$ of grape pomace. However, uses of grape pomace are limited but have been recycled as organic fertilizers, manure, and animal feed [23]. Because grape skins and seeds are the predominant constituents in the pomace, this biomass is a rich source of phenolic antioxidants $[20,21]$. We have previously extracted phenolic compounds from the skins of fresh Norton grapes which are wine grapes with unusual small sizes. The Norton grape skin contains $215.6 \mathrm{mg}$ phenolic compounds per gram of the extract [24]. The most abundant components in grape skin are those flavonoids. The concentration of catechin and epicatechin is 8.71 and $3.45 \mathrm{mg}$ per gram of the Norton skin extract [24]. Grape skin also contains a substantial amount of phenolic acids such as gallic acid, ferulic acid, caffeic acid, syringic acid, and p-coumaric acid with some being bound with sugars. Resveratrol is one of the most prominent bioactive components in grapes. Although resveratrol is predominantly contained in the grape skin, its concentration is only $0.21 \mathrm{mg}$ per gram of the extract based on our HPLC analysis [24].

It is estimated that approximately $60-70 \%$ of grape polyphenols exist in grape seeds [25]. In contrast to grape skins, grape seeds contain a main unique group of phenolic compounds, procyanidins, which are flavan-3-ol derivatives and are colorless in the pure state [26]. Oligomeric and polymeric procyanidins in grape seeds possess a broad spectrum of pharmacological, medicinal, and therapeutic properties and are one of the most potent natural antioxidants [2730]. They can be extracted during the latter stages of winemaking and are believed to contribute to color stability and organoleptic properties of wine [4-6]. In recent years, these proanthocyanidin compounds have extracted and purified from grape seeds and have become a common nutritional supplement. On the basis of structural characteristics, grape seed proanthocyanidins belong to condensed tannins. They mostly consist of $(+)$ catechin and $(-)$ epicatechin units, linked by $\mathrm{C}-4-\mathrm{C}-8$ or $\mathrm{C}-4-\mathrm{C}-6$ bonds and sometimes esterified by gallic acid on the epicatechin moiety(ies) [26]. These proanthocyanidins are the oligomer and polymer of flavan3 -ol with an average degree of polymerization (DP) ranging from 2 to $>15$ and an average molecular mass ranging from 578 to $>5000 \mathrm{Da}[1]$. The structures of grape dimeric and trimeric proanthocyanidins have been recently elucidated [26]. The proanthocyanidin content in grape seeds is highly dependent on their varieties and extraction procedures. In general, the galloylated procyanidins are present in considerably lower concentrations than the nongalloylated ones [31], and higher molecular weight polymers constitute the majority of proanthocyanidins in grape seeds [26].

\section{Antioxidant Properties of Grape Phenolic Compounds}

Antioxidant activities of grape phenolic compounds have been extensively investigated in vitro and in vivo. Studies from us and others showed that grape skin, seed, and pomace extracts possess potent free radical scavenging activities using oxygen radical absorbance capacity (ORAC), 2,2diphenyl-1-picrylhydrazyl (DPPH), and 2,2'-azino-bis(3ethylbenzothiazoline-6-sulphonic acid) (ABTS). Assays and some complex phenolics also show significant chelating activity on transition metal ions which are strong promoters of lipid peroxidation $[18,24,27,32]$. The antioxidant activities of grape phenolics have also been demonstrated in various model systems such as protecting low-density lipoprotein (LDL) against oxidation brought about by $\mathrm{Cu}^{2+}$, oxygen-centered radical-generating AAPH, or peroxynitritegenerating SIN-1 in vitro systems, preventing spleen cells from DNA damage induced by hydrogen peroxide $\left(\mathrm{H}_{2} \mathrm{O}_{2}\right)$, and reducing oxidative stress in PC12 cells induced by addition of $\mathrm{Fe}^{2+}$ and $t$-butyl hydroperoxide [33-35]. However, the in vivo studies examining antioxidant activity of grape extracts have shown inconsistent results. Some studies showed that dietary intake of grape antioxidants helps to prevent lipid oxidation and inhibit the production of reactive oxygen species (ROS). For instance, dietary supplementation of grape seed extract $(600 \mathrm{mg} /$ day $)$ for 4 weeks was shown to reduce oxidative stress and improve glutathione (GSH)/oxidized glutathione (GSSG) and total antioxidant status (TAOS) in a double-blinded randomized crossover human trial [9]. Another study also demonstrated that grape seed extract supplementation $(2 \times 300 \mathrm{mg} /$ day $)$ improved plasma antioxidant capacity in the high-cholesterol human subjects [36]. While other studies showed that dietary supplementation of grape juice, grape skin, or grape seed extracts exhibits either only a moderate antioxidative effect $[11,37,38]$ or a neutral effect in animals and humans [39-41]. We have recently found that 3-month dietary supplementation of grape skin and grape pomace antioxidant extracts $(0.2 \%$ in diet, equivalent to equivalent to approximately $960 \mathrm{mg}$ GSE/day for humans) showed no effects on oxidative stress in diet-induced obesity mice [41, 42]. These results are consolidated by a recent report which showed that dietary supplementation of grape skin extract $(1170 \mathrm{mg} /$ day $)$ had no significant effect on antioxidant enzymes including superoxide dismutase or catalase and also had no effect on 2aminoadipic semialdehyde (AAS) residues, a plasma protein oxidation product, or on malondialdehyde in plasma or in LDL, markers of lipoprotein oxidation in physically active individuals [43]. This inconsistency may be related to the low absorption of grape phenolics since the absorption rate of polyphenol antioxidants is generally less than $1 \%$ [44].

\section{Anticancer Properties of Grape Phenolic Compounds}

Grape antioxidants have drawn an increased attention for their potential anticancer effects. A number of studies suggest that the high consumption of grape components could be associated with the reduced risk of certain cancers such as breast cancer and colon cancer [45-47]. The anticancer effects of grape antioxidants have been demonstrated in in vitro and in vivo models [48-52]. Grape antioxidants 
have been shown to induce cell cycle arrest and apoptosis in cancer cells [53] as well as prevent carcinogenesis and cancer progression in rodent models $[54,55]$. Considering the diversity of grape antioxidants, it is very likely that these compounds are to exert potential anticancer activity by acting on multiple cellular events associated with tumor initiation, promotion, and progression. Proposed mechanisms of potential anticancer effects of grape antioxidants include antioxidant, anti-inflammatory, and antiproliferative activities [56]. Grape antioxidants could act as free radicals scavengers, and chelating agents help to reduce physiological reactive oxygen species (ROS) [57]. ROS is known as an important mediator of apoptosis since initiation and regulation of apoptosis is associated with modifications in the oxidative environment [58]. Study has shown that dietary intake of grape antioxidants reduced rat mucosal apoptosis via modulation of both mitochondrial and cytosolic antioxidant enzyme systems together with an increase in cellular glutathione (GSH): glutathione disulfide (GSSG) ratio, protecting normal colonic mucosa from reactive oxygen species (ROS) attack $[25,59]$. Grape antioxidants also exert anti-inflammatory activity which is believed to be associated with their chemopreventive effects $[25,41$, 42]. Cancer chemopreventive agents include nonsteroidal anti-inflammatory drugs (NSAIDs) such as indomethacin, piroxicam, and sulindac, all of which inhibit cyclooxygenase (COX) [60]. This inhibitory activity is relevant to cancer chemoprevention because COX catalyzes the conversion of arachidonic acid to proinflammatory substances such as prostaglandins, which can stimulate tumor cell growth and suppress immune surveillance $[60,61]$. Moreover, COX may activate carcinogens to more reactive substances that cause genetic damage [62]. A number of studies have demonstrated the inhibitory effects of whole grape extracts, individual grape antioxidants, or their mixture on COX activity and gene expression [63-65]. In addition, a study found that grape antioxidants exert an antitumor activity partially related to their immunopotentiating activities through the enhancements of lymphocyte proliferation, NK cell cytotoxicity, CD4+/CD8+ ratio, IL-2, and IFN- $\gamma$ productions [66].

Grape antioxidants are also shown to modify estrogen receptor (ER) and are therefore especially relevant for gynecological cancers such as breast cancer [67]. For example, some grape antioxidants such as resveratrol, quercetin, and catechin exhibit both estrogenic and antiestrogenic effects due to their structural similarity to the steroid hormone estrogen $[67,68]$. Resveratrol was reported to bind ER $\beta$ and $\operatorname{ER} \alpha$ with comparable affinity but that the estrogen agonist activity of resveratrol was greater with $\mathrm{ER} \beta$ than with $\mathrm{ER} \alpha$ [69]. The binding affinity of grape skin anthocyanidins (anthocyanin aglycones) to ER $\alpha$ was 10,000 - to 20,000-fold lower than that of the endogenous estrogen estradiol and these compounds at treatment levels of $10-20 \mu \mathrm{mols} / \mathrm{L}$ on MCF-7 cells exhibited a weak but statistically significant estrogenic activity [70]. However, in combination treatments with estradiol, three grape anthocyanidins showed antiestrogenic activity, which could be potentially explained by competition for the estrogen receptor and lower intrinsic activity of the phytoestrogens than estradiol [70]. It has been suggested that the number of hydroxy groups in grape pigments had a substantial effect on the estrogen activity. The presence of up to two hydroxy groups in the Bring of the molecular structure decreased the affinity of the anthocyanidins to the ER $\alpha$ [71]. Grape anthocyanidins showed estrogen-inducible cell proliferation in MCF-7 breast cancer cell line but not in the receptor-negative MDA-MB231 cell line. The fact that 4-hydroxytamoxifen, the receptor antagonist, can block the anthocyanidins-induced cell proliferation and combination treatments of anthocyanidins with estradiol-reduced proliferative activity of estradiol strongly suggest that the estrogenic activity of certain grape is relevant to its beneficial activity against estrogen-dependent cancers [70].

Epidermal growth factor receptor (EGFR) is a type I tyrosine kinase receptor belonging to a family of receptors that also includes HER2, HER3, and HER4. Aberrant EGFR activation, mediated primarily through changes in gene amplification and autocrine stimulation, appears to be a key factor in tumorigenesis, as well as an essential driving force for the aggressive growth behavior of cancer cells [72]. Grape antioxidants have been shown to inhibit expression of epidermal growth factor receptor (EGFR) in head and neck squamous cell carcinoma (HNSCC) cells which also caused an inhibition of the phosphorylation of extracellular signal-regulated kinase (ERK1/2), the highly conserved Ras/mitogen-activated protein kinase (MAPK)-dependent pathway (one of EGFR major downstream pathways) [57]. This effect is supported by another study that found that grape seed antioxidants inhibited constitutive activation of MAPK/ERK1/2 and MAPK/p38 in MDA-MB-468 cells [73]. The effects of grape antioxidants on cell cycle arrest are reported to be involved in promoting the expression of p21(Cip1)/p27(Kip1) protein G1-phase arrest [74]. Grape antioxidants can also target the transcription factor nuclear factor kappa B (NF- $\kappa \mathrm{B})$ by inhibiting its DNA-binding capacity to inhibit cancer cell invasion [75]. Recent in vitro and in vivo studies on potential anticancer properties of grape antioxidants are discussed as follows.

\section{In Vitro Anticancer Properties of Grape Phenolic Compounds}

Grape antioxidants especially grape seed proanthocyanidins (GSPs) show very promising inhibitory effects on a variety of cancer cells. Non-small-cell lung cancer (NSCLC) represents approximately $80 \%$ of total lung cancer cases, the leading cause of cancer-related deaths. GSPs have been shown to induce apoptosis of NSCLC cells: A549 and H1299, which are mediated through increased expression of proapoptotic protein Bax, decreased expression of antiapoptotic proteins $\mathrm{Bcl} 2$ and $\mathrm{Bcl}-\mathrm{xl}$, disruption of mitochondrial membrane potential, and activation of caspases 9, 3, and poly(ADPribose) polymerase (PARP) [76]. Overexpression of COX2 and prostaglandins (PG) is linked to a wide variety of human cancers. In vitro treatment of NSCLC cells (A549, $\mathrm{H} 1299, \mathrm{H} 460, \mathrm{H} 226$, and H157) with GSPs resulted in significant growth inhibition and induction of apoptosis, which were associated with the inhibitory effects of GSPs 
on the overexpression of COX-2 and prostaglandin (PG) E2 receptors (EP1 and EP4) in these cells [77].

Grape seed extract (GSE) was also found to selectively inhibit the growth and cause cell cycle arrest and apoptotic death in both Detroit 562 and FaDu HNSCC cells by activating DNA damage checkpoint cascade, including ataxia telangiectasia mutated/ataxia telangiectasia-Rad3related-checkpoint kinase 1/2-cell division cycle $25 \mathrm{C}$ as well as caspases 8, 9, and 3 [78]. In addition, GSEcaused accumulation of intracellular ROS was identified as a major mechanism of its effect for growth inhibition, DNA damage and apoptosis, which was remarkably reversed by antioxidant N-acetylcysteine [78]. GSPs have recently shown to concentration-dependent inhibit human cutaneous HNSCC cell invasion, which was associated with a reduction in the levels of epidermal growth factor receptor (EGFR) and the inhibition of the phosphorylation of ERK1/2, a member of mitogen-activated protein kinase family [57]. Additionally, inhibition of human cutaneous HNSCC cell invasion by GSPs was associated with reversal of epithelial-to-mesenchymal transition (EMT) process, which resulted in an increase in the levels of epithelial biomarker (E-cadherin) while loss of mesenchymal biomarkers (vimentin, fibronectin, and N-cadherin) in cells [57]. These data suggest a potential for GSPs to be developed and used for the prevention of invasion/metastasis of HNSCC cells.

Melanoma is the leading cause of death from skin disease, and treatment of human melanoma A375 and Hs294t cells with GSPs resulted in a concentration-dependent inhibition of invasion or cell migration of these cells, which was related to a significant reduction in the levels of COX-2 expression and PGE(2) production [79]. GSPs in vitro are also effective on oral squamous cell carcinoma (OSCC). OEC-M1 cells lead to cell cycle arrest by increasing the expression of $\mathrm{p} 21(\mathrm{Cip} 1) / \mathrm{p} 27$ (Kip1) protein without functioning mitochondria-mediated apoptosis, whereas GSP on SCC-25 cells inhibits cell proliferation via both G1-phase arrest and mitochondria-mediated apoptosis in a dosedependent manner as a result of alterations of Bcl-2 [74]. Moreover, GSP can inhibit the migration and invasion of both cells, which are associated with the suppression of matrix metalloproteinases (MMPs), MMP-2, and MMP-9 [74].

Studies investigating the effect of grape products on breast cancer also show promising results. A polyphenolic fraction isolated from grape seeds that is rich in procyanidins inhibits constitutive activation of MAPK/ERK1/2 and $\mathrm{MAPK} / \mathrm{p} 38$ and causes an induction of CDKI Cip1/p21 and a decrease in CDK4 in MDA-MB-468 cells [73]. Constitutive activation of ERK1/2 pathway has been shown to be associated with human breast carcinomas and derived cell lines for uncontrolled growth $[80,81]$. These effects of GSP result in a G1 arrest in cell cycle, followed by an irreversible inhibition of cell growth [73]. The activity is supported by another study which found that GSE upregulates p21 (Cip1) through redox-mediated activation of ERK1/2 pathway and posttranscriptional regulation leading to cell cycle arrest in colon carcinoma HT29 cells [82].
GSE is also protective against prostate cancer which was shown to inhibit histone acetyltransferases (HATs) in LNCaP cells, leading to decreased androgen-receptor- (AR) mediated transcription and cancer cell growth [83]. In addition, GSE can downregulate urokinase plasminogen activator (uPA) and DNA-binding activity of the transcription factor nuclear factor kappa $\mathrm{B}(\mathrm{NF}-\kappa \mathrm{B})$ in highly metastatic androgen-independent PC3 prostate cancer cells and therefore inhibits cell invasion [75]. Study found that procyanidins from wild grape seeds can regulate AREmediated enzyme expression via Nrf2 coupled with p38 and PI3K/Akt pathway in HepG2 cells and could be used as a potential natural chemopreventive agent through Nrf2/AREmediated phase II detoxifying/antioxidant enzymes induction via p38 and PI3K/Akt pathway [84]. Growth of certain colon cancer cells is also inhibited by GSE which exerts both antiproliferative and apoptotic effects on Caco 2 and HCT8 colon cancer cells, and its inhibitive effects were stronger than isolated procyanidins, suggesting a potential additive or synergistic effect among the grape seed components [85]. Another study found that the combination of resveratrol, a prominent grape skin component, and grape seed extract induces much more pronounced apoptosis in colon cancer cells, which is strongly correlated with p53 levels and Bax: Bcl-2 ratio [86].

\section{In Vivo Anticancer Properties of Grape Phenolic Compounds}

Most in vivo studies of anticancer properties of grape components focused on GSE or proanthocyanidin fraction of GSE (e.g., GSPs). In 1999, Agarwal and his colleagues conducted a thorough review on in vivo efficacy and potential working mechanisms of GSE and grape-based products against a variety of cancers [87]. Therefore, in this paper we discussed the in vivo studies that were conducted since 1999. Dietary intake of GSE (0.2\% GSE wt/wt in diet) decreased HNSCC Detroit 562 and FaDu xenograft tumor growth by 67 and $65 \%(P<0.001)$, respectively. Xenografts from GSE-fed groups showed decreased proliferation but increased DNA damage and apoptosis [78]. However, the exact molecular mechanisms are remained to be elucidated. Administration of 50,100 , or $200 \mathrm{mg}$ GSPs/kg body weight of mice by oral gavage ( $5 \mathrm{~d}$ /week) markedly inhibited the growth of NSCLC A549 and H1299 lung tumor xenografts in athymic nude mice, which was associated with the induction of apoptotic cell death, increased expression of Bax, reduced expression of antiapoptotic proteins, and activation of caspase- 3 in tumor xenograft cells [76], suggesting a consistency between the observations of in vitro and in vivo studies. The growthinhibitory effect of dietary GSPs $(0.5 \%$, w/w) was also shown on the NSCLC xenografts, and the inhibition was associated with the inhibition of COX-2, PGE(2), and PGE(2) receptors (EP1, EP3, and EP4) in tumors [77]. GSE may also be effective in the prevention of certain types of cancers. A recent study showed that dietary supplementation of grape seed extract $(0.25$ or $0.5 \%(\mathrm{w} / \mathrm{w})$ caused strong chemopreventive efficacy in Fischer 344 rats against azoxymethane- (AOM)induced aberrant crypt foci (ACF) formation (as much as 
$60 \%$ reduction in number of ACF and $66 \%$ reduction in crypt multiplicity) [88].

The literature search on various databases found only one human trial on grape products and cancer treatment that examined the role of grape products specifically grape seed proanthocyanidin extract in patients with breast induration following radiotherapy for breast cancer and found no significant effect. With respect to preventive effect, a human study showed that 8-week dietary supplementation of grape juice $(480 \mathrm{~mL} /$ day $)$ reduced lymphocyte DNA damage by reducing the formation of reactive oxygen species by as much as $15 \%$ [81], suggesting that a potential anticarcinogenic role for grape products by providing antioxidant protection.

In summary, with respect to cancer prevention and treatment, grape seed extracts or its proanthocyanidins have received most investigation for their potential anticancer activities. Some studies show very promising potential of GSE as an anticancer agent. However, most available reports are focusing on their in vitro activities and mechanisms. Since the absorption of these phenolic compounds is limited, the dose responses of GSE and its components need to be determined in animals and humans as well as its in vivo mechanisms. The potential use of grape skin and seed extracts in cancer prevention has great potential, and further investigation into this exciting field is warranted.

\section{References}

[1] S. S. Percival, "Grape consumption supports immunity in animals and humans," Journal of Nutrition, vol. 139, no. 9, pp. 1801S-1805S, 2009.

[2] G. Schamel, "Geography versus brands in a global wine market," Agribusiness, vol. 22, pp. 363-374, 2006.

[3] M. A. Vivier and I. S. Pretorius, "Genetically tailored grapevines for the wine industry," Trends in Biotechnology, vol. 20, no. 11, pp. 472-478, 2002.

[4] P. This, T. Lacombe, and M. R. Thomas, "Historical origins and genetic diversity of wine grapes," Trends in Genetics, vol. 22, no. 9, pp. 511-519, 2006.

[5] B. Hankinson, V. N. M. Rao, and C. J. B. Smit, "Viscoelastic and histological properties of grape skins," Journal of Food Science, vol. 42, pp. 632-635, 1977.

[6] A. Bellincontro, D. De Santis, R. Botondi, I. Villa, and F. Mencarelli, "Different postharvest dehydration rates affect quality characteristics and volatile compounds of Malvasia, Trebbiano and Sangiovese grapes for wine production," Journal of the Science of Food and Agriculture, vol. 84, no. 13, pp. 1791-1800, 2004.

[7] H. H. H. Feringa, D. A. Laskey, J. E. Dickson, and C. I. Coleman, "The effect of grape seed extract on cardiovascular risk markers: a meta-analysis of randomized controlled trials," Journal of the American Dietetic Association, vol. 111, no. 8, pp. 1173-1181, 2011.

[8] P. B. Mellen, K. R. Daniel, K. B. Brosnihan, K. J. Hansen, and D. M. Herrington, "Effect of muscadine grape seed supplementation on vascular function in subjects with or at risk for cardiovascular disease: a randomized crossover trial," Journal of the American College of Nutrition, vol. 29, no. 5, pp. 469-475, 2010.

[9] P. Kar, D. Laight, H. K. Rooprai, K. M. Shaw, and M. Cummings, "Effects of grape seed extract in Type 2 diabetic subjects at high cardiovascular risk: a double blind randomized placebo controlled trial examining metabolic markers, vascular tone, inflammation, oxidative stress and insulin sensitivity," Diabetic Medicine, vol. 26, no. 5, pp. 526-531, 2009.

[10] P. Castilla, A. Dávalos, J. L. Teruel et al., "Comparative effects of dietary supplementation with red grape juice and vitamin E on production of superoxide by circulating neutrophil NADPH oxidase in hemodialysis patients," American Journal of Clinical Nutrition, vol. 87, no. 4, pp. 1053-1061, 2008.

[11] P. Castilla, R. Echarri, A. Dávalos et al., "Concentrated red grape juice exerts antioxidant, hypolipidemic, and antiinflammatory effects in both hemodialysis patients and healthy subjects," American Journal of Clinical Nutrition, vol. 84, no. 1, pp. 252-262, 2006.

[12] S. Brooker, S. Martin, A. Pearson et al., "Double-blind, placebo-controlled, randomised phase II trial of IH636 grape seed proanthocyanidin extract (GSPE) in patients with radiation-induced breast induration," Radiotherapy and Oncology, vol. 79, no. 1, pp. 45-51, 2006.

[13] H. G. Preuss, D. Wallerstedt, N. Talpur et al., "Effects of niacinbound chromium and grape seed proanthocyanidin extract on the lipid profile of hypercholesterolemic subjects: a pilot study," Journal of Medicine, vol. 31, no. 5-6, pp. 227-246, 2000.

[14] S. M. Nadtochiy and E. K. Redman, "Mediterranean diet and cardioprotection: the role of nitrite, polyunsaturated fatty acids, and polyphenols," Nutrition, vol. 27, no. 7-8, pp. 733744, 2011.

[15] L. M. Vislocky and M. L. Fernandez, "Biomedical effects of grape products," Nutrition Reviews, vol. 68, no. 11, pp. 656670, 2010.

[16] J. K. Prasain, S. H. Carlson, and J. M. Wyss, "Flavonoids and age-related disease: risk, benefits and critical windows," Maturitas, vol. 66, no. 2, pp. 163-171, 2010.

[17] R. F. Frayne, "Direct analysis of the major organic components in grape must and wine using high performance liquid chromatography," American Journal of Enology and Viticulture, vol. 37, pp. 281-287, 1986.

[18] S. Hogan, L. Zhang, J. Li, B. Zoecklein, and K. Zhou, "Antioxidant properties and bioactive components of Norton (Vitis aestivalis) and Cabernet Franc (Vitis vinifera) wine grapes," LWT_Food Science and Technology, vol. 42, no. 7, pp. 1269-1274, 2009.

[19] M. Careri, C. Corradini, L. Elviri, I. Nicoletti, and I. Zagnoni, "Direct HPLC analysis of quercetin and trans-resveratrol in red wine, grape, and winemaking byproducts," Journal of Agricultural and Food Chemistry, vol. 51, no. 18, pp. 52265231, 2003.

[20] D. Kammerer, A. Claus, R. Carle, and A. Schieber, "Polyphenol screening of pomace from red and white grape varieties (Vitis vinifera L.) by HPLC-DAD-MS/MS," Journal of Agricultural and Food Chemistry, vol. 52, no. 14, pp. 4360-4367, 2004.

[21] Y. Lu and L. Yeap Foo, "The polyphenol constituents of grape pomace," Food Chemistry, vol. 65, no. 1, pp. 1-8, 1999.

[22] M. A. Bustamante, R. Moral, C. Paredes, A. Pérez-Espinosa, J. Moreno-Caselles, and M. D. Pérez-Murcia, "Agrochemical characterisation of the solid by-products and residues from the winery and distillery industry," Waste Management, vol. 28, no. 2, pp. 372-380, 2008.

[23] S. Hogan, L. Zhang, J. Li, S. Sun, C. Canning, and K. Zhou, "Antioxidant rich grape pomace extract suppresses postprandial hyperglycemia in diabetic mice by specifically inhibiting alpha-glucosidase," Nutrition and Metabolism, vol. 7, article 71, 2010. 
[24] L. Zhang, S. Hogan, J. Li et al., "Grape skin extract inhibits mammalian intestinal $\alpha$-glucosidase activity and suppresses postprandial glycemic response in streptozocin-treated mice," Food Chemistry, vol. 126, no. 2, pp. 466-471, 2011.

[25] J. Zhao, J. Wang, Y. Chen, and R. Agarwal, "Anti-tumorpromoting activity of a polyphenolic fraction isolated from grape seeds in the mouse skin two-stage initiation-promotion protocol and identification of procyanidin B5-3'-gallate as the most effective antioxidant constituent," Carcinogenesis, vol. 20, no. 9, pp. 1737-1745, 1999.

[26] C. Prieur, J. Rigaud, V. Cheynier, and M. Moutounet, "Oligomeric and polymeric procyanidins from grape seeds," Phytochemistry, vol. 36, no. 3, pp. 781-784, 1994.

[27] G. K. Jayaprakasha, R. P. Singh, and K. K. Sakariah, "Antioxidant activity of grape seed (Vitis vinifera) extracts on peroxidation models in vitro," Food Chemistry, vol. 73, no. 3, pp. 285-290, 2001.

[28] D. Bagchi, A. Garg, R. L. Krohn et al., "Protective effects of grape seed proanthocyanidins and selected antioxidants against TPA-induced hepatic and brain lipid peroxidation and DNA fragmentation, and peritoneal macrophage activation in mice," General Pharmacology, vol. 30, no. 5, pp. 771-776, 1998.

[29] M. Sato, G. Maulik, P. S. Ray, D. Bagchi, and D. K. Das, "Cardioprotective effects of grape seed proanthocyanidin against ischemic reperfusion injury," Journal of Molecular and Cellular Cardiology, vol. 31, no. 6, pp. 1289-1297, 1999.

[30] X. Ye, R. L. Krohn, W. Liu et al., "The cytotoxic effects of a novel IH636 grape seed proanthocyanidin extract on cultured human cancer cells," Molecular and Cellular Biochemistry, vol. 196, no. 1-2, pp. 99-108, 1999.

[31] T. Fuleki and J. M. R. Da Silva, "Catechin and procyanidin composition of seeds from grape cultivars grown in Ontario," Journal of Agricultural and Food Chemistry, vol. 45, no. 4, pp. 1156-1160, 1997.

[32] C. Negro, L. Tommasi, and A. Miceli, "Phenolic compounds and antioxidant activity from red grape marc extracts," Bioresource Technology, vol. 87, no. 1, pp. 41-44, 2003.

[33] M. Shafiee, M. A. Carbonneau, N. Urban, B. Descomps, and C. L. Leger, "Grape and grape seed extract capacities at protecting LDL against oxidation generated by $\mathrm{Cu} 2+$, AAPH or SIN1 and at decreasing superoxide THP-1 cell production. A comparison to other extracts or compounds," Free Radical Research, vol. 37, no. 5, pp. 573-584, 2003.

[34] P. Fan and H. Lou, "Effects of polyphenols from grape seeds on oxidative damage to cellular DNA," Molecular and Cellular Biochemistry, vol. 267, no. 1-2, pp. 67-74, 2004.

[35] S. Chanvitayapongs, B. Draczynska-Lusiak, and A. Y. Sun, "Amelioration of oxidative stress by antioxidants and resveratrol in PC12 cells," NeuroReport, vol. 8, no. 6, pp. 1499-1502, 1997.

[36] J. A. Vinson, J. Proch, and P. Bose, "MegaNatural Gold grapeseed extract: in vitro antioxidant and in vivo human supplementation studies," Journal of Medicinal Food, vol. 4, no. 1, pp. 17-26, 2001.

[37] L. Yuan, L. Meng, W. Ma et al., "Impact of apple and grape juice consumption on the antioxidant status in healthy subjects," International Journal of Food Sciences and Nutrition, vol. 62 , no. 8, pp. 844-850, 2011.

[38] R. Soares De Moura, F. S. Costa Viana, M. A. V. Souza et al., "Antihypertensive, vasodilator and antioxidant effects of a vinifera grape skin extract," Journal of Pharmacy and Pharmacology, vol. 54, no. 11, pp. 1515-1520, 2002.

[39] J. H. Hollis, J. A. Houchins, J. B. Blumberg, and R. D. Mattes, "Effects of concord grape juice on appetite, diet, body weight, lipid profile, and antioxidant status of adults.," Journal of the American College of Nutrition, vol. 28, no. 5, pp. 574-582, 2009.

[40] E. Sadowska-Krępa, B. Kłapcińska, E. Kimsa, and R. Karpiński, "Effects of supplemetation with red grape skin polyphenolic extract and interval swimming test on the blood antioxidant status in healthy men," Medicina Sportiva, vol. 12, pp. 1-7, 2008.

[41] S. Hogan, C. Canning, S. Sun, X. Sun, and K. Zhou, "Effects of grape pomace antioxidant extract on oxidative stress and inflammation in diet induced obese mice," Journal of Agricultural and Food Chemistry, vol. 58, no. 21, pp. 1125011256, 2010.

[42] S. Hogan, C. Canning, S. Sun, X. Sun, H. Kadouh, and K. Zhou, "Dietary supplementation of grape skin extract improves glycemia and inflammation in diet-induced obese mice fed a western high fat diet," Journal of Agricultural and Food Chemistry, vol. 59, no. 7, pp. 3035-3041, 2011.

[43] J. F. Young, L. O. Dragsted, B. Daneshvar, S. T. Lauridsen, M. Hansen, and B. Sandström, "The effect of grape-skin extract on oxidative status," British Journal of Nutrition, vol. 84, no. 4, pp. 505-513, 2000.

[44] D. M. Goldberg, J. Yan, and G. J. Soleas, "Absorption of three wine-related polyphenols in three different matrices by healthy subjects," Clinical Biochemistry, vol. 36, no. 1, pp. 7987, 2003.

[45] J. M. Falcao, J. A. Dias, A. C. Miranda, C. N. Leitao, M. M. Lacerda, and L. Cayolla Da Motta, "Red wine consumption and gastric cancer in Portugal: a case-control study," European Journal of Cancer Prevention, vol. 3, no. 3, pp. 269-276, 1994.

[46] J. F. Viel, J. M. Perarnau, B. Challier, and I. Faivre-Nappez, "Alcoholic calories, red wine consumption and breast cancer among premenopausal women," European Journal of Epidemiology, vol. 13, no. 6, pp. 639-643, 1997.

[47] M. G. L. Hertog, D. Kromhout, C. Aravanis et al., "Flavonoid intake and long-term risk of coronary heart disease and cancer in the Seven Countries Study," Archives of Internal Medicine, vol. 155, no. 4, pp. 381-386, 1995.

[48] G. J. Soleas, L. Grass, P. D. Josephy, D. M. Goldberg, and E. P. Diamandis, "A comparison of the anticarcinogenic properties of four red wine polyphenols," Clinical Biochemistry, vol. 35, no. 2, pp. 119-124, 2002.

[49] D. M. Morré and D. J. Morré, "Anticancer activity of grape and grape skin extracts alone and combined with green tea infusions," Cancer Letters, vol. 238, no. 2, pp. 202-209, 2006.

[50] A. J. Clifford, S. E. Ebeler, J. D. Ebeler et al., "Delayed tumor onset in transgenic mice fed an amino acid-based diet supplemented with red wine solids," American Journal of Clinical Nutrition, vol. 64, no. 5, pp. 748-756, 1996.

[51] H. Kim, P. Hall, M. Smith et al., "Chemoprevention by grape seed extract and genistein in carcinogen-induced mammary cancer in rats is diet dependent," Journal of Nutrition, vol. 134, no. 12, pp. 3445S-3452S, 2004.

[52] K. J. Jung, M. A. Wallig, and K. W. Singletary, "Purple grape juice inhibits 7,12-dimethylbenz[a]anthracene (DMBA)-induced rat mammary tumorigenesis and in vivo DMBA-DNA adduct formation," Cancer Letters, vol. 233, no. 2, pp. 279-288, 2006.

[53] B. B. Aggarwal, A. Bhardwaj, R. S. Aggarwal, N. P. Seeram, S. Shishodia, and Y. Takada, "Role of resveratrol in prevention and therapy of cancer: preclinical and clinical studies," Anticancer Research, vol. 24, no. 5 A, pp. 2783-2840, 2004.

[54] S. Garvin, K. Öllinger, and C. Dabrosin, "Resveratrol induces apoptosis and inhibits angiogenesis in human breast cancer 
xenografts in vivo," Cancer Letters, vol. 231, no. 1, pp. 113-122, 2006.

[55] S. E. Ebeler, C. A. Brenneman, G. S. Kim et al., "Dietary catechin delays tumor onset in a transgenic mouse model," American Journal of Clinical Nutrition, vol. 76, no. 4, pp. 865872, 2002.

[56] N. P. Seeram, L. S. Adams, S. M. Henning et al., “in vitro antiproliferative, apoptotic and antioxidant activities of punicalagin, ellagic acid and a total pomegranate tannin extract are enhanced in combination with other polyphenols as found in pomegranate juice," Journal of Nutritional Biochemistry, vol. 16, no. 6, pp. 360-367, 2005.

[57] Q. Sun, R. Prasad, E. Rosenthal, and S. K. Katiyar, "Grape seed proanthocyanidins inhibit the invasive potential of head and neck cutaneous squamous cell carcinoma cells by targeting EGFR expression and epithelial-to-mesenchymal transition," BMC Complementary and Alternative Medicine, vol. 11, article 134, 2011.

[58] J. M. Matés and F. M. Sánchez-Jiménez, "Role of reactive oxygen species in apoptosis: implications for cancer therapy," International Journal of Biochemistry and Cell Biology, vol. 32, no. 2, pp. 157-170, 2000.

[59] M. E. Lpez-Oliva, A. Agis-Torres, I. Goñi, and E. MuozMartnez, "Grape antioxidant dietary fibre reduced apoptosis and induced a pro-reducing shift in the glutathione redox state of the rat proximal colonic mucosa," British Journal of Nutrition, vol. 103, no. 8, pp. 1110-1117, 2010.

[60] M. Jang, L. Cai, G. O. Udeani et al., "Cancer chemopreventive activity of resveratrol, a natural product derived from grapes," Science, vol. 275, no. 5297, pp. 218-220, 1997.

[61] O. J. Plescia, A. H. Smith, and K. Grinwich, "Subversion of immune system by tumor cells and role of prostaglandins," Proceedings of the National Academy of Sciences of the United States of America, vol. 72, no. 5, pp. 1848-1851, 1975.

[62] T. V. Zenser, M. B. Mattammal, and R. W. Wise, "Prostaglandin $\mathrm{H}$ synthase-catalyzed activation of benzidine: a model to assess pharmacologic intervention of the initiation of chemical carcinogenesis," Journal of Pharmacology and Experimental Therapeutics, vol. 227, no. 3, pp. 545-550, 1983.

[63] P. Waffo-Téguo, M. E. Hawthorne, M. Cuendet et al., "Potential cancer-chemopreventive activities of wine stilbenoids and flavans extracted from grape (Vitis vinifera) cell cultures," Nutrition and Cancer, vol. 40, no. 2, pp. 173-179, 2001.

[64] S. K. Katiyar, "Grape seed proanthocyanidines and skin cancer prevention: inhibition of oxidative stress and protection of immune system," Molecular Nutrition and Food Research, vol. 52, no. 1, pp. S71-S76, 2008.

[65] M. Malik, C. Zhao, N. Schoene, M. M. Guisti, M. P. Moyer, and B. A. Magnuson, "Anthocyanin-rich extract from Aronia meloncarpa E. induces a cell cycle block in colon cancer but not normal colonic cells," Nutrition and Cancer, vol. 46, no. 2, pp. 186-196, 2003.

[66] X. Y. Zhang, W. G. Li, Y. J. Wu et al., "Proanthocyanidin from grape seeds potentiates anti-tumor activity of doxorubicin via immunomodulatory mechanism," International Immunopharmacology, vol. 5, no. 7-8, pp. 1247-1257, 2005.

[67] C. M. Klinge, K. E. Risinger, M. B. Watts, V. Beck, R. Eder, and A. Jungbauer, "Estrogenic activity in white and red wine extracts," Journal of Agricultural and Food Chemistry, vol. 51, no. 7, pp. 1850-1857, 2003

[68] A. Schlachterman, F. Valle, K. M. Wall et al., "Combined resveratrol, quercetin, and catechin treatment reduces breast tumor growth in a nude mouse model," Translational Oncology, vol. 1, pp. 19-27, 2008.
[69] J. L. Bowers, V. V. Tyulmenkov, S. C. Jernigan, and C. M. Klinge, "Resveratrol acts as a mixed agonist/antagonist for estrogen receptors $\alpha$ and $\beta$," Endocrinology, vol. 141, no. 10, pp. 3657-3667, 2000.

[70] E. Schmitt and H. Stopper, "Estrogenic activity of naturally occurring anthocyanidins," Nutrition and Cancer, vol. 41, no. 1-2, pp. 145-149, 2001.

[71] J. Lu, D.-M. Wu, Y.-L. Zheng, B. Hu, W. Cheng, and Z.-F. Zhang, "Purple sweet potato color attenuates domoic acidinduced cognitive deficits by promoting estrogen receptor- $\alpha$ mediated mitochondrial biogenesis signaling in mice," Free Radical Biology and Medicine, vol. 52, no. 3, pp. 646-659, 2012.

[72] D. S. Salomon, R. Brandt, F. Ciardiello, and N. Normanno, "Epidermal growth factor-related peptides and their receptors in human malignancies," Critical Reviews in Oncology/Hematology, vol. 19, no. 3, pp. 183-232, 1995.

[73] C. Agarwal, Y. Sharma, J. Zhao, and R. Agarwal, "A polyphenolic fraction from grape seeds causes irreversible growth inhibition of breast carcinoma MDA-MB468 cells by inhibiting mitogen- activated protein kinases activation and inducing G1 arrest and differentiation," Clinical Cancer Research, vol. 6, no. 7, pp. 2921-2930, 2000.

[74] Y.-S. Lin, S.-F. Chen, C.-L. Liu, and S. Nieh, "The chemoadjuvant potential of grape seed procyanidins on p53-related cell death in oral cancer cells," Journal of Oral Pathology and Medicine, vol. 41, no. 4, pp. 322-331, 2012.

[75] R. Uchino, R. Madhyastha, H. Madhyastha et al., "NF $\kappa$ Bdependent regulation of urokinase plasminogen activator by proanthocyanidin-rich grape seed extract: effect on invasion by prostate cancer cells," Blood Coagulation and Fibrinolysis, vol. 21, no. 6, pp. 528-533, 2010.

[76] T. Singh, S. D. Sharma, and S. K. Katiyar, "Grape proanthocyanidins induce apoptosis by loss of mitochondrial membrane potential of human non-small cell lung cancer cells in vitro and in vivo," PLoS ONE, vol. 6, no. 11, Article ID e27444, 2011.

[77] S. D. Sharma, S. M. Meeran, and S. K. Katiyar, "Proanthocyanidins inhibit in vitro and in vivo growth of human nonsmall cell lung cancer cells by inhibiting the prostaglandin e2 and prostaglandin e2 receptors," Molecular Cancer Therapeutics, vol. 9, no. 3, pp. 569-580, 2010.

[78] S. Shrotriya, G. Deep, M. Gu et al., "Generation of reactive oxygen species by grape seed extract causes irreparable DNA damage leading to $\mathrm{G}_{2} / \mathrm{M}$ arrest and apoptosis selectively in head and neck squamous cell carcinoma cells," Carcinogenesis, vol. 33, no. 4, pp. 848-858, 2012.

[79] M. Vaid, T. Singh, and S. K. Katiyar, "Grape seed Proanthocyanidins inhibit Melanoma cell invasiveness by reduction of PGE2 synthesis and reversal of Epithelial-to-Mesenchymal transition," PLoS ONE, vol. 6, no. 6, Article ID e21539, 2011.

[80] C. A. Lange, J. K. Richer, T. Shen, and K. B. Horwitz, "Convergence of progesterone and epidermal growth factor signaling in breast cancer: potentiation of mitogen-activated protein kinase pathways," Journal of Biological Chemistry, vol. 273, no. 47, pp. 31308-31316, 1998.

[81] Y. K. Park, E. Park, J. S. Kim, and M. H. Kang, "Daily grape juice consumption reduces oxidative DNA damage and plasma free radical levels in healthy Koreans," Mutation Research, vol. 529, no. 1-2, pp. 77-86, 2003.

[82] M. Kaur, A. Tyagi, R. P. Singh, R. A. Sclafani, R. Agarwal, and C. Agarwal, "Grape seed extract upregulates p21 (Cip1) through redox-mediated activation of ERK1/2 and posttranscriptional regulation leading to cell cycle arrest in colon 
carcinoma HT29 cells," Molecular Carcinogenesis, vol. 50, no. 7, pp. 553-562, 2011.

[83] S. Y. Park, Y. H. Lee, K. C. Choi et al., "Grape seed extract regulates androgen receptor-mediated transcription in prostate cancer cells through potent anti-histone acetyltransferase activity," Journal of Medicinal Food, vol. 14, no. 1-2, pp. 9-16, 2011.

[84] M.-J. Bak, M. Jun, and W.-S. Jeong, "Procyanidins from wild grape (Vitis amurensis) seeds regulate ARE-mediated enzyme expression via Nrf2 coupled with p38 and PI3K/Akt pathway in HepG2 cells," International Journal of Molecular Sciences, vol. 13, no. 1, pp. 801-818, 2012.

[85] S. Dinicola, A. Cucina, A. Pasqualato et al., "Antiproliferative and apoptotic effects triggered by grape seed extract (GSE) versus epigallocatechin and procyanidins on colon cancer cell lines," International Journal of Molecular Sciences, vol. 13, no. 1, pp. 651-664, 2012.

[86] S. Radhakrishnan, L. Reddivari, R. Sclafani, U. N. Das, and J. Vanamala, "Resveratrol potentiates grape seed extract induced human colon cancer cell apoptosis," Frontiers in Bioscience, vol. 3, pp. 1509-1523, 2011.

[87] M. Kaur, C. Agarwal, and R. Agarwal, "Anticancer and cancer chemopreventive potential of grape seed extract and other grape-based products," Journal of Nutrition, vol. 139, no. 9, pp. 1806S-1812S, 2009.

[88] B. Velmurugan, R. P. Singh, R. Agarwal, and C. Agarwal, "Dietary-feeding of grape seed extract prevents azoxymethane-induced colonic aberrant crypt foci formation in fischer 344 rats," Molecular Carcinogenesis, vol. 49, no. 7, pp. 641-652, 2010. 


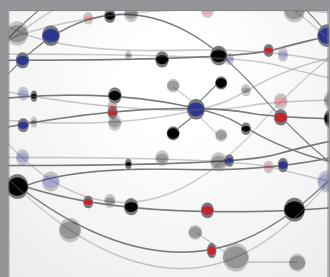

The Scientific World Journal
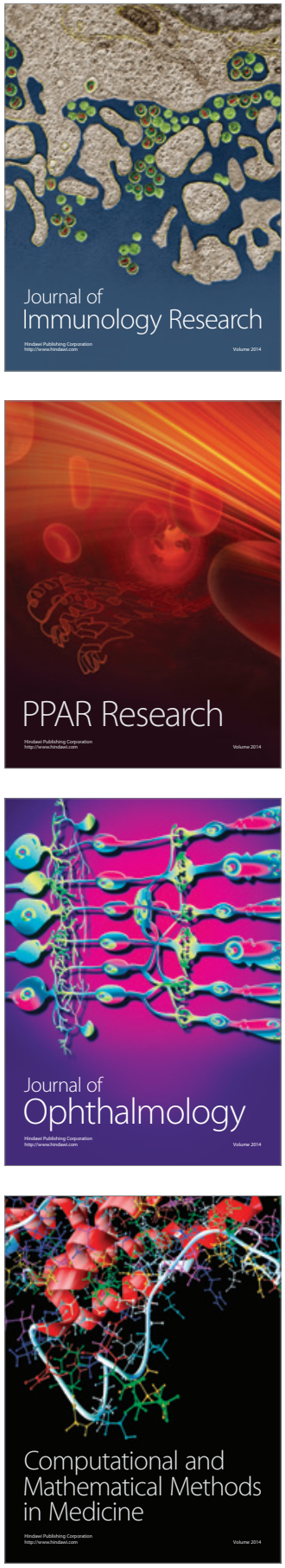

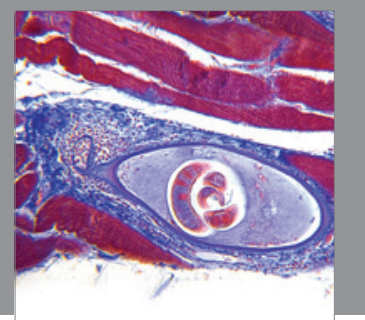

Gastroenterology

Research and Practice
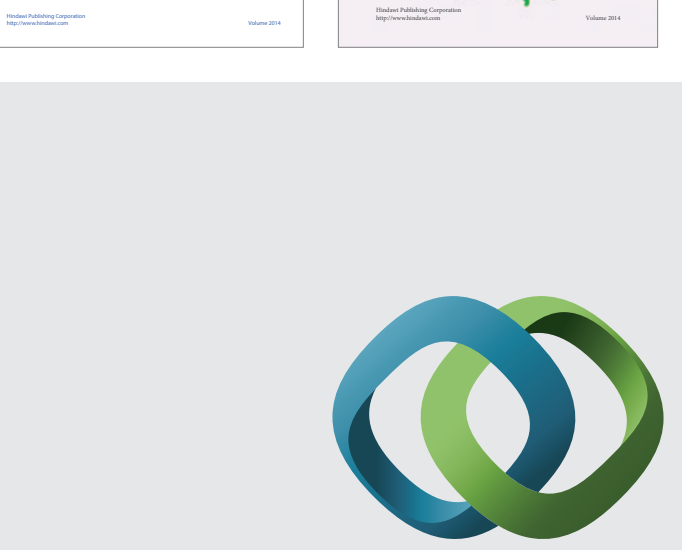

\section{Hindawi}

Submit your manuscripts at

http://www.hindawi.com
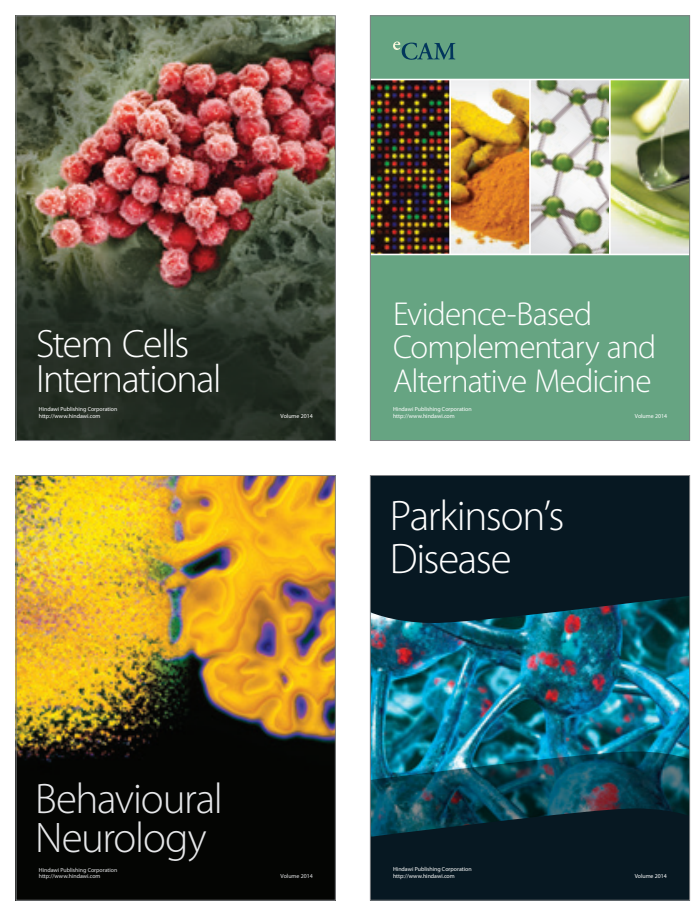

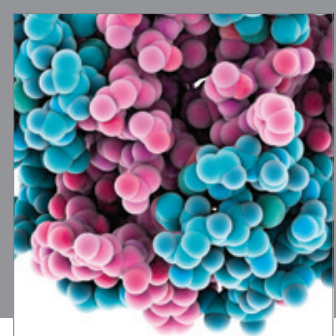

Journal of
Diabetes Research

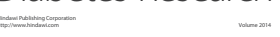

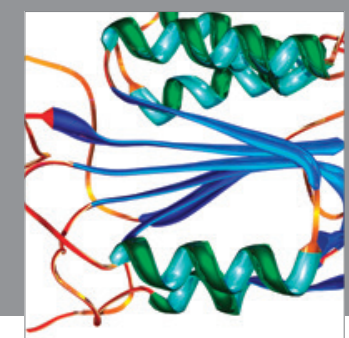

Disease Markers
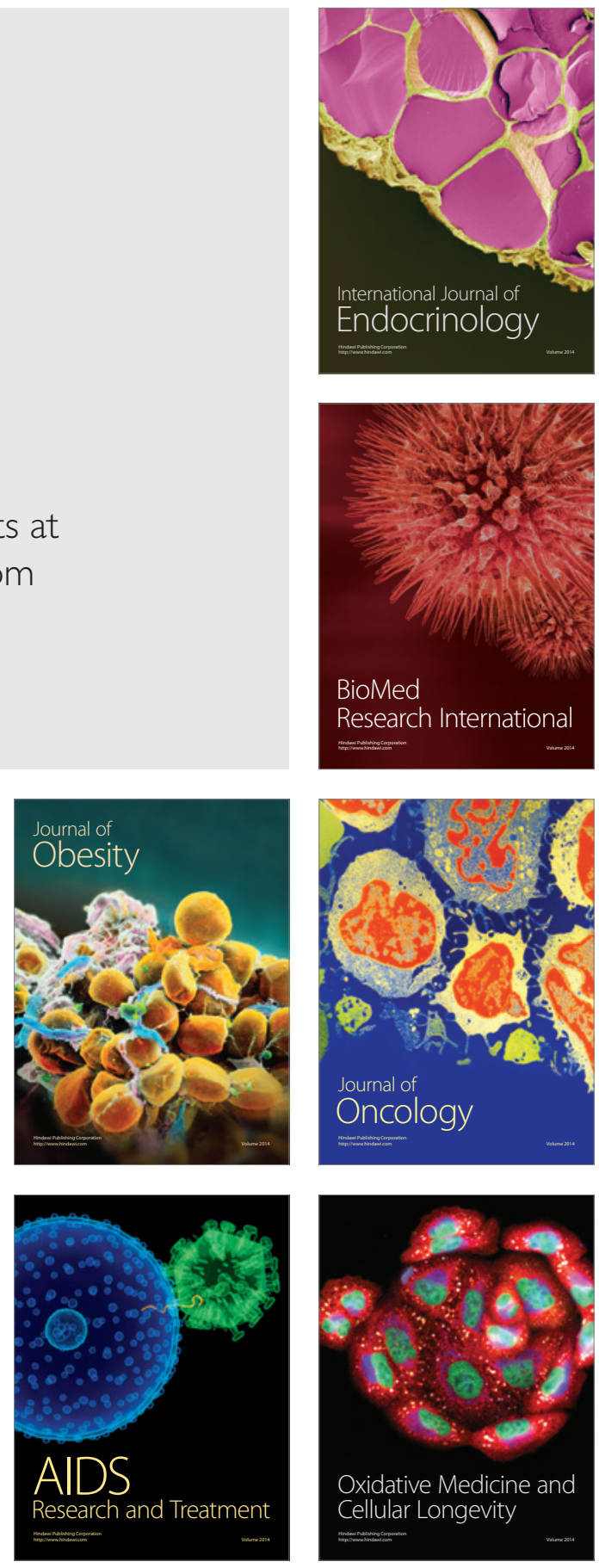